\title{
Effect of Depth of
}

Flow on Discharge of Bed Material

By BRUCE R. COLBY

STUDIES OF FLOW IN ALLUVIAL CHANNELS

GEOLOGICAL SURVEY WATER-SUPPLY PAPER 1498-D

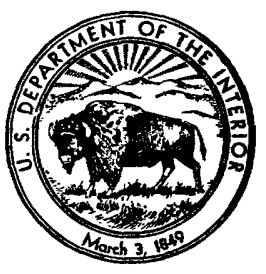


UNITED STATES DEPARTMENT OF THE INTERIOR

STEWART L. UDALL, Secretary

GEOLOGICAL SURVEY

Thomas B. Nolan, Director

For sale by the Superintendent of Documents, U.S. Government Printing Office Washington 25, D.C. - Price 15 cents (paper cover) 


\section{CONTENTS}

Abstract

Abstract.......... D-1

Introduction

Definitions_._.

Depth effect computed from the Einstein procedure

Depth effect experimentally determined

General reason for the depth effect._... 7

Depth effect for shear velocity

Depth effect for stream power.... 9

Conclusions.......... 11

References........ 12

\section{ILLUSTRATIONS}

FIgURE 1. Qualitative effect of depth on the relationship between mean velocity and discharge of bed material as computed from a procedure somewhat revised from Einstein's .............

2. Effect of depth on the relationship between mean velocity and empirically determined discharges of bed material at $60^{\circ} \mathrm{F}$

D-4

6

3. Schematic diagram showing the general reasons for variability of effect of depth on the relationship of discharge of ma-

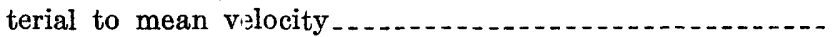

4. Effect of depth on the relationship between discharge of bedmaterial at $60^{\circ} \mathrm{F}$ and shear velocity with respect to the

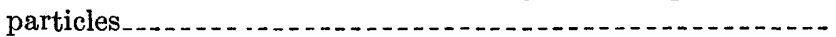





\title{
EFFEGT OF DEPTH OF FLOW ON DISGHARGE OF BED MATERIAL
}

By Bruce R. Colby

\begin{abstract}
Computations with the Einstein procedure and an empirical analysis of data from flumes and natural streams agree qualitatively in showing a complex effect of depth of flow on the relationship of discharge of bed material to mean velocity. The effect of increasing the depth is in the opposite direction at low mean velocities from what it is at high mean velocities and is almost negligible at some intermediate velocities. Depth of flow has an equally complex and varied effect on the relationship between discharge of bed material and stream power and has, except at low shears, a large but simpler effect on the discharge of bed material as related to shear velocity with respect to the sediment particles.
\end{abstract}

\section{INTRODUCTION}

In most flume experiments, the range of depth is relatively small and the discharge of bedload frequently is on the order of magnitude of the discharge of suspended bed material. Hence the variable effect of depth of flow on the relationship between discharge of bed material, which at high velocities may be mostly in suspension, and parameters of flow is sometimes overlooked or misunderstood, especially for natural streams.

The purpose of this paper is to give at least a rough idea of the effect of depth on relationships between the discharge of bed material and such flow parameters as shear velocity with respect to the particles, mean velocity, and stream power. The theoretical and empirical derivation of graphs of discharge of bed material per foot of stream width as a function of depth and mean velocity for flow over sand beds is described first. The effect of depth is then explained in general terms on the basis of these graphs and other broad relationships.

This paper is based on computations and studies that were made partly while the writer was working for the Agricultural Research Service, U.S. Department of Agriculture. Information from the files of that agency and the Geological Survey was used to define figures 2 and 4. 


\section{DEFINITIONS}

A few of the terms used in this discussion are defined as follows:

Bedload is the sediment that moves by sliding, rolling, or skipping on or very near the streambed and is supported mainly by the bed rather than by the turbulence of the flow.

Bed material is a size classification and includes the sizes of sediment particles that are found in appreciable quantity near the surface of the streambed, but the bed material may be transported anywhere between the bed and the water surface.

Discharge, as applied to sediment movement, is a time rate of transportation of dry weight of sediment through a cross section.

Measured discharge of bed material is the discharge of bed material that can be determined from streamflow and depth-integrated sediment samples, which generally are obtained by sampling the flow from the water surface to within 0.3 or 0.4 foot of the streambed.

Shear velocity with respect to the grains or particles is Einstein's concept (1950) and may be defined as the shear velocity that can be computed from the energy gradient and a particular hydraulic radius $R^{\prime}$. The square root of the ratio of $R^{\prime}$ to the hydraulic radius $R$ equals the ratio of the actual mean velocity to the mean velocity that would exist if all resistance were due to the particles on the bed and none to the configuration of the bed and banks. The configuration of the bed and banks of sand-bed streams causes resistance to flow, not only because of general changes in channel form but also because of ripples and dunes on the bed. The resistance caused by ripples and dunes is usually large and may change rapidly at times.

Total discharge of bed material is the discharge of all the bed material that passes through a stream cross section.

Stream power per unit area of the bed is the product of shear and mean velocity or $\gamma d S \bar{u}$, in which $\gamma$ is the weight of the water-sediment mixture per unit volume, $d$ is the depth of flow, $S$ is the energy gradient, and $\bar{u}$ is the mean velocity.

Unmeasured sediment discharge is the difference between total sediment discharge and measured sediment discharge. It is nearly all discharge of bed material, and hence is about equivalent to the difference between total and measured discharge of bed material.

The symbol " $z$ " is an exponential measure of the vertical distribution of concentration of sediment of uniform size or of a narrow size range. Under the assumptions for which it was theoretically derived, it equals $v_{s} /(k \sqrt{g R S})$, in which $v_{s}$ is the fall velocity, $g$ is the gravity constant, and $k$ is the turbulence constant. 


\section{DEPTH EFFECT COMPUTED FROM THE EINSTEIN FROCEDURE}

One approach to understanding the relationship of discharge of bed material to characteristics of the cross section and flow is to make many computations with some formula or procedure for computing bed-material discharges. The procedure described by Einstein (1950) is one of the most comprehensive and detailed methods for computing discharges of bed material by at least partly theoretical relationships and was, therefore, selected for the computations. The sediment of the streambed was assumed to be cohesionless sand of which 35,50 , and 65 percent by weight was finer than $0.35,0.40$, and 0.45 millimeter, respectively.

Discharges of bed material per foot of stream width were computed, according to a somewhat revised Einstein procedure, for water temperatures of $40^{\circ}, 60^{\circ}$, and $80^{\circ} \mathrm{F}$ and for wide ranges of depth and velocity. The revisions of the procedure consisted mainly of computing shear velocities with respect to the particles from mean velocities and determining $z^{\prime}$ s partly from experimental data, rather than from theory only. The revised $z$ 's for flow over dune beds were more realistic than those that might be computed as Einstein suggested, but they were too small for flow over plane or antidune beds and hence gave too large computed discharges of bed material for high mean velocities. However, the computed results show qualitatively (fig. 1) the relative effects of velocity, depth, and water temperature on the discharge of the assumed bed material.

Mean velocity is obviously the major factor in determining the discharge of the assumed bed material according to figure 1. (However, its apparent effect is overstated at mean velocities of $5 \mathrm{fps}$ or more.) The computed effect of temperature is reasonably consistent although the effect increases in general as depth of flow increases. The effect of depth is variable. At a mean velocity of 5 feet per second, depth has little computed effect; about as much bed material would be discharged per foot of width at a depth of 1 foot as at a depth of 100 feet. As the depth increases, the discharge of bed material increases at high constant mean velocities and decreases at low constant mean velocities.

If computations similar to those that were used to define figure 1 had been made for a coarser bed material, the mean velocity at which depth has little effect would have been greater than 5 feet per second; if they had been made for finer bed material, the mean velocity at which depth has little effect would have been less than 5 feet per second.

If computed concentrations had been plotted instead of discharge of bed material, the effect of depth would be large except for high mean 


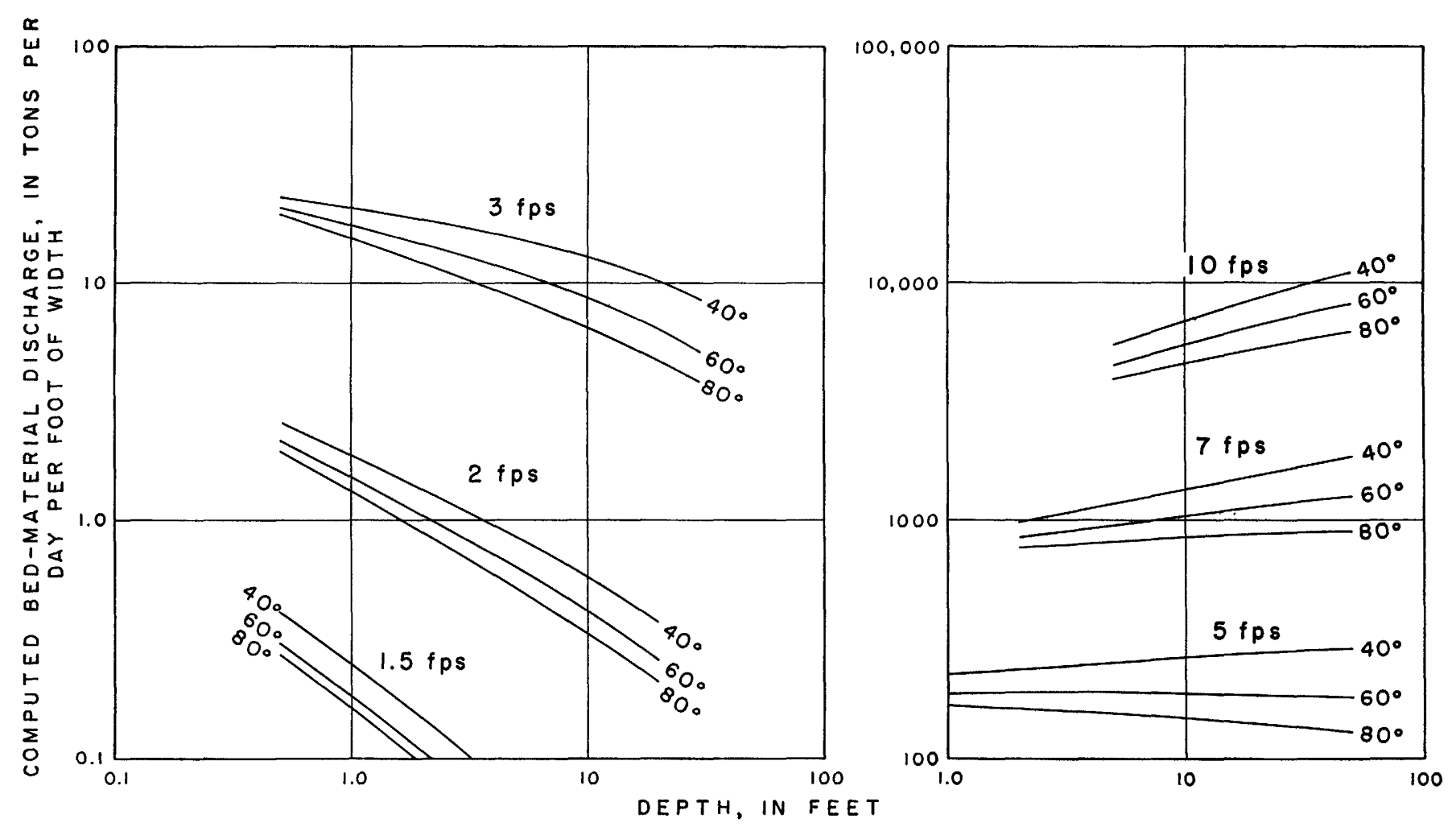


velocities and small enough sediment particles so that the vertical distribution of suspended sediment would be almost uniform.

\section{DEPTH EFFECT EXPERIMENTALLY DETERMINED}

Of course, a figure similar to figure 1 can be defined empirically if enough information is available for wide ranges of depth and velocity. Hence, many determinations of total discharge of bed material per foot of width and concurrent mean velocities were obtained and plotted. These determinations were mostly for flume studies, although some field determinations of total discharge of bed material were available particularly for Middle Loup River near Dunning, Nebr. (Hubbell and Matejka, 1959), and Niobrara River near Cody, Nebr. (Colby and Hembree, 1955). These field determinations of total discharge of bed material were based on measurements at cross sections where velocity and turbulence were high enough to suspend practically the entire sediment discharge of the stream. Widths and mean velocities were computed at nearby cross sections where the flow was over beds of sand whose median diameter was determined by sampling.

At cross sections of some natural streams that have beds of sand, the total discharges of bed material usually were not determined, and only the measured discharges were known. If the stream widths, mean velocities, and other necessary information were observed as the sediment samples were taken the total discharge of bed material could be computed by using the modified Einstein procedure (Colby and Hembree, 1955) or from the relation of unmeasured sediment discharge to mean velocity (Colby, 1957). Although accurate field determinations of total discharge of bed material are preferable to partly computed discharges, the computed discharges were used for the Rio Grande, the Mississippi River, and some other streams for which better information was not available.

The total discharges of bed material were first roughly adjusted to a water temperature of $60^{\circ} \mathrm{F}$ and were then used to define individual graphs empirically for median particle sizes of bed material of $0.1,0.2$, 0.3 , and 0.4 millimeter. Obviously, most median particle sizes and mean velocities were not exactly equal to desired quantities such as 0.20 millimeter and 4.0 feet per second but might be, for example, 0.24 millimeter and 3.7 feet per second. Hence, a complex system of judgment and graphic analysis was used to interpolate and extrapolate the basic information until a fairly consistent set of smooth graphs was obtained. The graphs, of which figure 2 is one, are somewhat inexact and conventionalized. They are intended to apply to fields streams rather than to laboratory flumes, which usually have more uniform lateral distributions of depth and velocity than field 


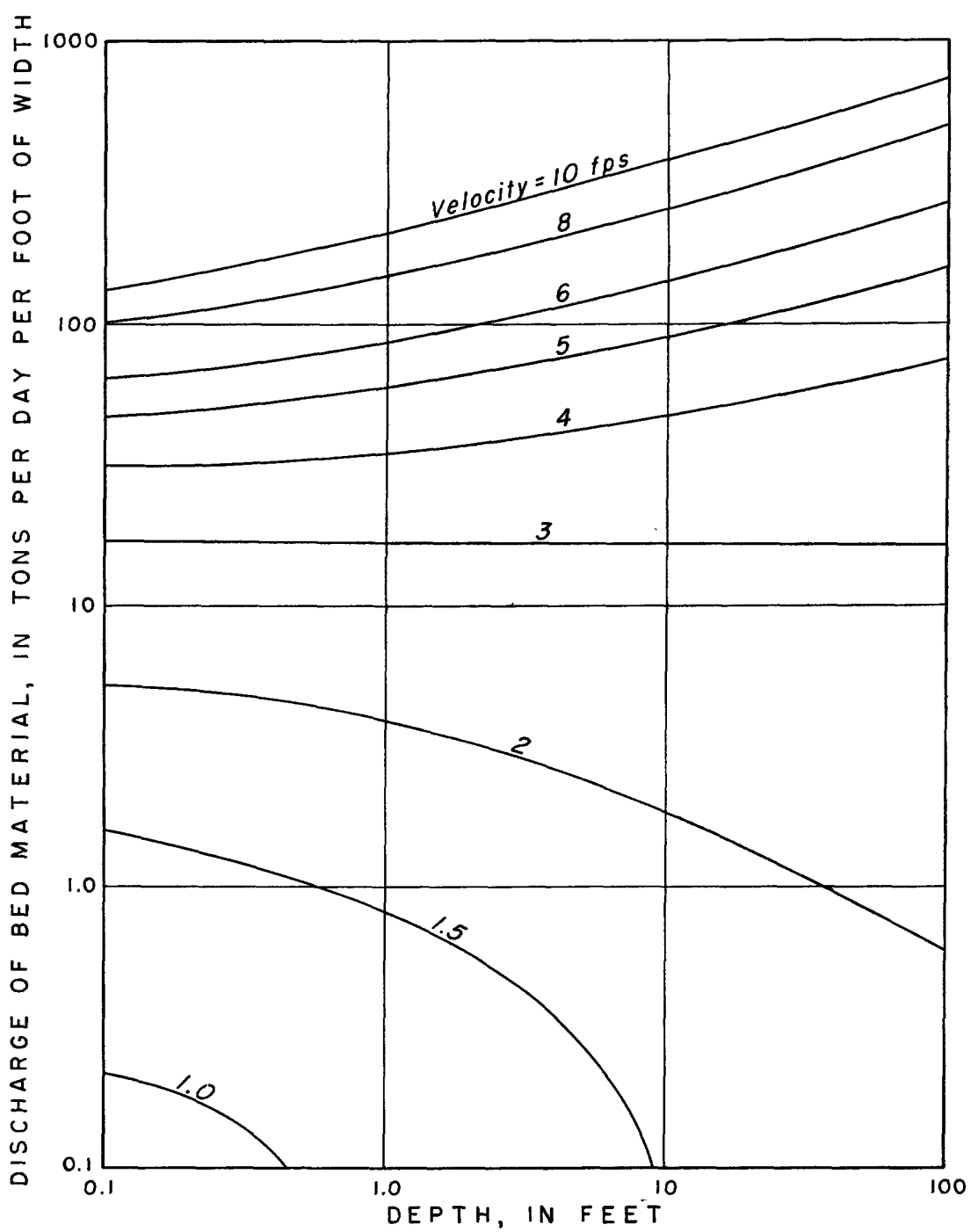

Figure 2.-Effect of depth on the relationship between mean velocity and empirically determined dise charges of bed material $\left(0.3-\mathrm{mm}\right.$ median diameter) at $60^{\circ} \mathrm{F}$.

streams. Also, the median size reported for sediment in a flume investigation is generally for the material that is placed in the flume rather than for the sediment that is actually resting at the surface of the bed during flow, when some of the finest sediment may be in suspension. In experiments such as those by Gilbert (1914), some selective sorting must occur during a series of runs even though the range of particle sizes is small.

The graph for bed material whose median diameter is 0.3 millimeter (fig. 2) is probably as well defined as any of the four empirically 
determined graphs and is, therefore, used as a basis for consideration of the effect of depth. However, the effect of depth on the relation between discharge of bed material and mean velocity varies not only with velocity but also with size of the bed material when the mean velocity is consant. For example, the mean velocities at which depth has little apparent effect according to the empirically defined graphs are about 1.6, 2.0, and 4.0 feet per second for bed materials of $0.1-$, $0.2-$, and 0.4-millimeter median diameters as compared to 3.0 feet per second for bed material of 0.3-millimeter median diameter. Of course, the line for a velocity of 3.0 feet per second on figure 2, if more accurately defined, might not be exactly horizontal through part or any of its length.

Qualitatively, the effects of depth on the relation between discharge of bed material and mean velocity are roughly comparable (figs. 1 and 2) whether determined from the Einstein procedure or defined empirically, even though the sizes of bed material differ somewhat. That is, the indicated effect of depth is insignificant for some intermediate mean velocity, whereas at higher constant mean velocities the discharge of bed material increases as depth increases and at lower constant mean velocities the discharge decreases as depth increases. The effect of depth is small at those velocities and depths. that characterize many sand-bed streams when they are discharging much of their bed-material loads. Hence, a sand-bed stream at a particular cross section generally has a reasonably good relationship. between discharge of bed material per foot of stream width and mean velocity when water temperature is constant, because the variation in depth and in lateral distribution of velocity at a given mean velocity is usually rather small. If cross sections of the same or different streams have comparable bed material, the relationship for one cross. section may also hold reasonably well for others especially at intermediate mean velocities but less well, perhaps, at high and low velocities for which depth effects are larger.

Although factors other than velocity, depth, and water temperature may affect the discharge of bed material, a group of graphs each similar to that on figure 2 but for a different size of bed material gives a good practical basis for estimating discharge of bed material. However, the uses and adjustments of such graphs for computing or estimating the discharge of bed material in sand-bed streams are beyond the scope of this paper.

\section{GENERAL REASON FOR THE DEPTH EFFECT}

The variable effect of depth on the discharges of bed material is. easily understood in broad outline, although the actual computation of such discharges for different depths is inexact and complicated. 
If mean velocity is low-say 2 feet per second-and water flows in a shallow stream over a sand bed whose median diameter is 0.3 or 0.4 millimeter, a certain amount of bed material, as indicated by the curves of velocity and concentration on figure 3 , will be discharged

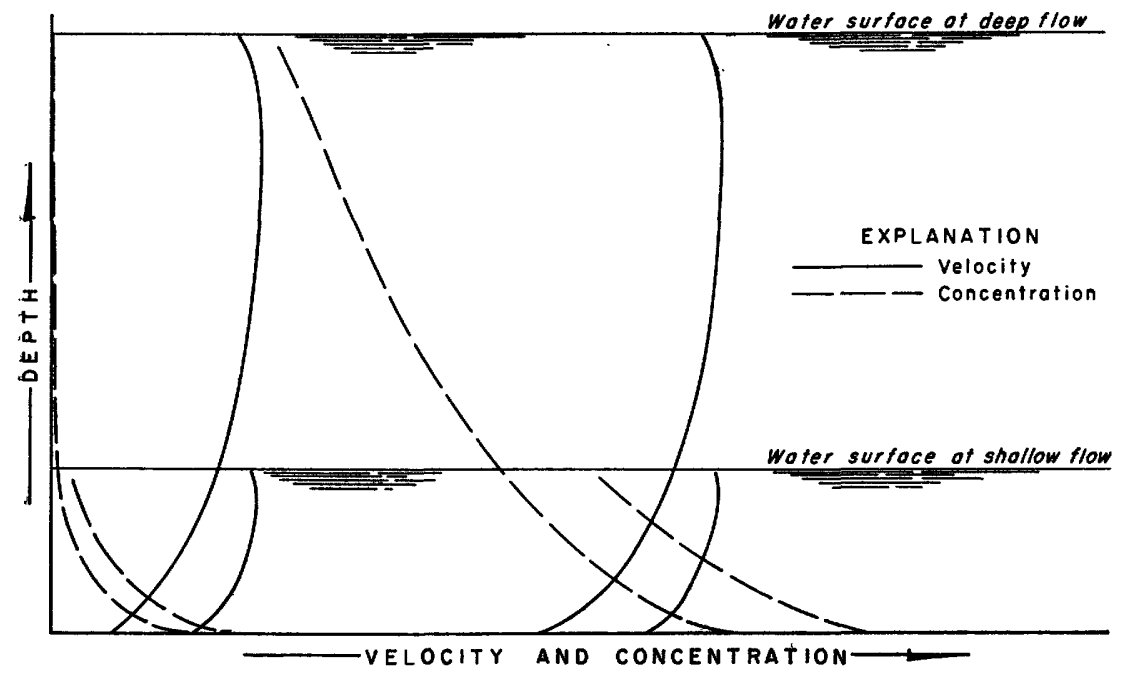

FISURE 3.-Schematic diagram showing the general reasons for variability of effect of depth on the relationship of bed-material discharge to mean velocity.

mostly near the streambed. If the depth of flow is greatly increased and the mean velocity is kept constant, the velocity near the streambed will decrease and the discharge of bed material both at the bed and throughout the original shallow depth of flow will decrease. Only a little bed material will be discharged in suspension in the added depth of flow. Hence, the total discharge of bed material is likely to be less for a given low mean velocity when the flow is deep than when it is shallow. On the other hand, if the mean velocity is high-say 6 feet per second - the discharge of bed material in a shallow flow is greater than that in a layer of equal depth at the bottom of a deep flow because of the difference in the velocity near the streambed. However, the difference in discharge of bed material near the bed is more than balanced by the discharge in the superposed layer of the deeper flow. (See fig. 3.)

To a considerable extent, the effect of increasing the mean velocity over a bed of constant particle size is equivalent to decreasing the particle size at constant velocity. Therefore, the effect of depth for fine bed material at moderately low mean velocity may be about equivalent to that for coarser bed material at some higher.mean velocity. 


\section{DEPTH EFFECT FOR SHEAR VELOCITY}

If Chezy's $C$ were constant, the same sort of effect of depth would apply to relationships between discharge of bed material and shear or shear velocity as applies to the relationships of discharge of bed material to mean velocity. However, Chezy's $C$ usually varies with depth and bed configuration. Also, as has been shown by Brooks (1958), shear is a poor measure of discharge of either water or sediment for certain conditions of flow and sand beds. Hence, the data of figure 2 were transposed to show the effect of depth on the relationship between discharge of bed material and shear with respect to the particles.

Shear velocity with respect to the particles was computed from a velocity equation given by Keulegan and used by Einstein (1950, p. 10):

in which-

$$
\bar{u}=5.75 u_{*}^{\prime} \log \left(12.27 d x / k_{s}\right)
$$

$\bar{u}$ is the mean velocity

$u_{*}{ }^{\prime}$ is the shear velocity with respect to the particles and equals $\sqrt{g R^{\prime} S}$

$d$ is the depth of flow

$x$ is a dimensionless parameter for the transition between hydraulically smooth and hydraulically rough boundaries and is a function of particle size, water temperature, and $u_{*}{ }^{\prime}$

$k_{z}$ is the grain roughness of the bed and was assumed to be 0.00115 foot $(0.35 \mathrm{~mm})$ for a median diameter of 0.30 millimeter

The equation was solved graphically by trial and error for values of $u_{*}{ }^{\prime}$ for different depths and mean velocities.

When the information on figure 2 was replotted on figure 4 in terms of $u_{*}{ }^{\prime}$ rather than mean velocity, a different pattern of depth effect appeared. The indicated effect of depth is small at low shear velocities with respect to the particles but increases rapidly as these velocities increase. Thus, figure 4 indicates that the effect of depth can be neglected at very low shear velocities, but large adjustments for this effect are required at nearly all flows that have practical significance in natural streams. However, this depth effect is always in the same direction.

\section{DEPTH EFFECT FOR STREAM POWER}

Bagnold (1960) has recently suggested the use of stream power as a measure of sediment discharge. In more familiar units and terminology than his, stream power of a volume of water in a uniform reach of river, $L$ units long and $W$ units wide, at steady flow equals the product of the weight of the water in the reach and the distance that the a verage elevation of the water decreases in unit time. Hence, the stream power for low concentrations of sediment and dissolved 


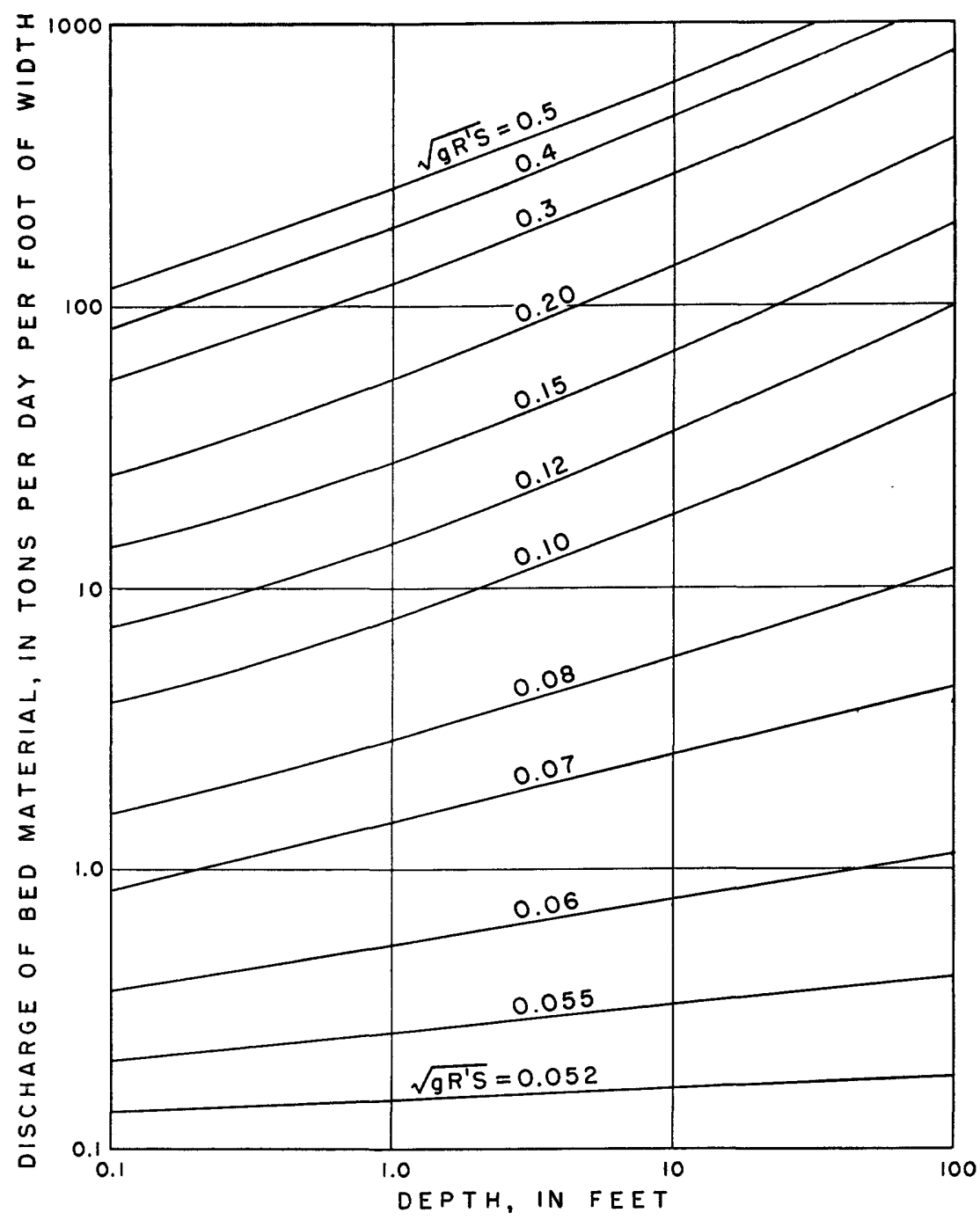

FigURE 4.-Effect of depth on the relationship between discharge of bed material at $60^{\circ} \mathrm{F}$ and shear velocity with respect to the particles.

solids and in pound-foot-second units is $62.4 L W d \bar{u} S$. For unit width and length of channel the stream power is $62.4 d S \bar{u}$ or is the product of shear and mean velocity.

If Chezy's $C$ is constant and a change in depth is compensated by an inverse change in energy gradient, the effect of depth on the relation of discharge of bed material to stream power is like that indicated by figure 2 . That is, if the mean velocity is 3 feet per second, median diameter is 0.3 millimeter, and shear is constant; the indicated 
discharge of bed material remains unchanged as the depth increases. For a lower mean velocity such as 1.5 feet per second, the discharge of bed material decreases rapidly as the depth increases at constant shear; for mean velocities higher than 3 feet per second, the discharge of bed material increases as depth increases at constant shear.

If Chezy's $C$ varies, as it does, for example, when the bed configuration changes, mean velocity will not be proportional to the shear, and the effect of depth on the relationship of bed material discharge to stream power becomes even more complex. In other words, a given percentage change in any one of the variables $\bar{u}, d$, or $S$ is not necessarily equivalent to an equal percentage change in either of the other two.

If all resistance to flow is caused by particle roughness, the shear is proportional to the square of shear velocity with respect to the particles and the stream power is proportional to the product of $\left(u_{*}^{\prime}\right)^{2}$ and $\bar{u}$. The effect of depth under this assumption is a combination of effects that are indicated by figures 2 and 4 . At constant low velocities and shears, the discharge of bed material decreases as depth increases; whereas at constant high velocities and shears, the discharge of bed material increases as depth increases.

\section{CONCLUSIONS}

The relation of discharge of bed material per foot of stream width to mean velocity, to shear velocity with respect to the particles, or to stream power vary, sometimes widely and complexly, with changes in depth. At constant low mean velocity an increase in depth reduces the discharge of bed material, but at constant high mean velocity the effect of depth is reversed. At some intermediate velocities, which are frequently the velocities at which most of the bed material is transported in natural streams, the effect of depth is usually small.

Depth has a somewhat similar but more complex effect on the relation of discharge of bed material to stream power, because stream power is a compound parameter that equals the product of shear and mean velocity.

Discharge of bed material at constant shear velocity with respect to the particles increases slowly with depth at low shears but increases rapidly with depth at higher shears. Practically, this effect of depth has the advantage of being always in the same direction as compared to the variable effect of depth on the relations that involve mean velocity or stream power. It has the disadvantage of being large throughout the usual range of significant flows in natural streams.

The effect of depth varies with particle size at constant mean velocity, constant shear velocity with respect to the particles, or constant stream power. For example, the effect of depth is small or 
negligible at mean velocities of about 1.6, 2.0, 3.0, and 4.0 feet per second for bed materials whose median sizes are about $0.1,0.2,0.3$, and 0.4 millimeter, respectively.

\section{REFERENCES}

Bagnold, R. A., 1960, Sediment discharge and stream power-a preliminary announcement: U.S. Geol. Survey Circ. 421, 23 p.

Brooks, N. H., 1958, Mechanies of streams with movable beds of fine sand: Am. Soc. Civil Engineers Trans., v. 120, p. 526-594.

Colby, B. R., 1957, Relationship of unmeasured sediment discharge to mean velocity: Am. Geophys. Union. Trans., v. 38, p. 708-717.

Colby, B. R., and Hembree, C. H., 1955, Computations of total sediment discharge, Niobrara River near Cody, Nebraska: U.S. Geol. Survey WaterSupply Paper 1357, $187 \mathrm{p}$.

Einstein, H. A., 1950, The bed-load function for sediment transportation in open channel flows: U.S. Dept. Agr. Tech. Bull. 1026, 71 p.

Gilbert, G. K., 1914, The transportation of debris by running water: U.S. Geol. Survey Prof. Paper 86, 263 p.

Hubbell, D. W., and Matejka, D. Q., 1959, Investigations of sediment transportation, Middle Loup River at Dunning, Nebraska: U.S. Geol. Survey WaterSupply Paper 1476, $123 \mathrm{p}$. 